\title{
Acute Onset Paraplegia Due to Thoracic Angiolipoma: A Case Report and Review of the Literature
}

\author{
KaraaslanBurak ${ }^{1}$ ÖcalÖzgür*2, ŞENOL Yiğit $\mathrm{Can}^{2}$, Aksogan, Yiğit ${ }^{4}$, AkarcaFahire Göknur ${ }^{3}$ \\ and Emmez Hakan ${ }^{4}$ \\ ${ }^{1}$ Department of Neurosurgery,ÇubukHalilŞıvgın State Hospital,Turkey \\ ${ }^{2}$ Department of Neurosurgery,Ankara Bilkent City Hospital, Turkey \\ ${ }^{3}$ Department of Pathology, Faculty of Medicine, Turkey \\ ${ }^{4}$ Department of Neurosurgery,Faculty of Medicine, Turkey \\ *Corresponding author: ÖcalÖzgür, Department of Neurosurgery, Ankara Bilkent City Hospital, Ankara, Turkey
}

ARTICLE INFO

Received: 宷 April 11, 2020

Published: 幽 April 23, 2020

Citation: KaraaslanBurak, ÖcalÖzgür, ŞENOL Yiğit C, Aksogan, Yiğit, et al. Acute Onset Paraplegia Due to Thoracic Angiolipoma: A Case Report and Review of the Literature. Biomed J Sci \& Tech Res 27(2)2020. BJSTR. MS.ID.004459.

Keywords: Spinal Angiolipoma; Spinal Extradural Tumor; Paraplegia

\section{ABSTRACT}

Background: Spinal angiolipomas are rare and benign tumors which are composed of mature adipose tissue and blood vessels. Thoracic epidural region is the most common location of spinal angiolipomas.

Clinical Description: A 51-year-old female presented with chronical back pain for 1 year. There was no pregnancy, trauma or another pathological history. Lumbar stabilization was performed at another hospital for spondylolisthesis. After 2 months of operation, the patient suffered from acute onset paraplegia. Radiological examination referred that extradural lesion located at T6-T9 level which was causing severe spinal cord compression. T7-T8 hemilaminectomy performed without disruption of the facet joint. And extradural adipose-like tumor was removed totally. Motor improvement achieved immediately after operation. And complete neurological recovery achieved at post-operative 48 hours.

Conclusion: Hemodynamic or adipose tissue alterations may trigger acute neurological deterioration at the spinal angiolipomas. In our case patient had a weight gain history after first operation. MRI is essential diagnostic tool for these lesions. Surgical treatment for spinal angiolipomas has good outcomes even in subtotal resection and/or at the complete paraplegia.

\section{Introduction}

Angiolipomas are subcutaneous benign lesions. Although angiolipomas are usually located at subcutaneous region, rarely they may locate at spinal canal. Spinal angiolipomas contains mature adipose tissue and blood vessels. Spinal angiolipomas (SAL) constitutes $0.14-1.2 \%$ of spinal tumors and $2-3 \%$ of extradural spinal tumors [1,2]. The most common presenting symptoms of SAL are chronic back pain, sensorial findings and muscle weakness [3]. Thoracic epidural region is the most common location of SAL [4]. Most of the SAL presents with progressive course. This type of findings is usually associated with progressive spinal cord compression. However, some cases of SAL are manifest with acute neurological finding. There are some hypotheses about etiopathogenesis of acute manifestation. Hormonal imbalance, pregnancy and weight gain have been shown to be risk factors for the development of acute neurological findings in SAL [5]. Surgical treatment has good outcomes regardless of preoperative neurological finding even in subtotal resection $[6,7]$. In our case we report presentation of acute onset paraplegia with previous back pain and weight gain history. 


\section{Case Presentation}

A 51-year-old female presented with chronical back pain without pregnancy, trauma or another pathological history. Magnetic resonance imagining (MRI) showed Grade1 anterololisthesis in the L4-5 level. Lumbar stabilization without posterior decompression was performed at another hospital for spondylolisthesis. Patient had weight gain due to immobilization because of lumbar stabilization operation and back pain. After 2months of post-operation, the patient presented with acute paraplegia. The patient was referred to our clinic for clinical investigation and treatment. Neurological examination showed flaccid paraplegia, hyperreflexia and bilateral positive babinski sign of bilateral lower extremity. Laboratory investigations revealed no abnormalities about infection. MRI showed posterior epidural lesion at T6-T9 level. On T1-weighted and T2-weighted MRI examination the tumor was homogeneously hyperintense. Prominent spinal cord compression was at T7-T8 level. T7-T8 hemilaminectomy performed without disruption of the facet joint. Intraoperatively yellow, firm adipose-like epidural lesion was found which was causing severe spinal cord compression. There was no invasion into dura matter or bone structures by lesion. The lesion was different from normal epidural fat tissue. The tumor had a good cleavage plan from dura mater. Extradural lesion was removed totally. The dura was not opened. Post operative period was uneventful. Muscular weakness improvement achieved immediately after operation. And complete neurological recovery achieved at post-operative 48 hours (Figures 1 \& 2).
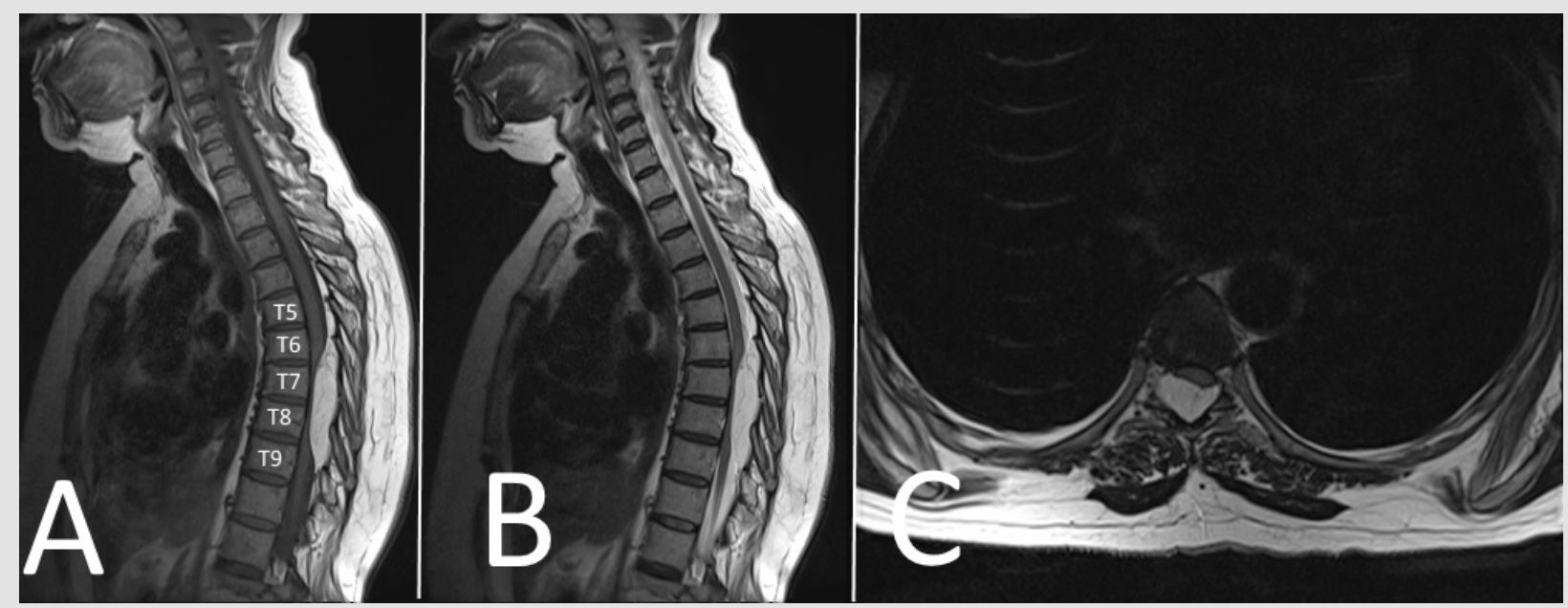

Figure 1:

Sagital and

Axial T1- weighted MRI showing spindle-shaped hyperintense extradural tumor at T6-T9.

Sagital and

Axial T2-weighted MRI showing hyperintense lesion causing severe spinal cord compression.

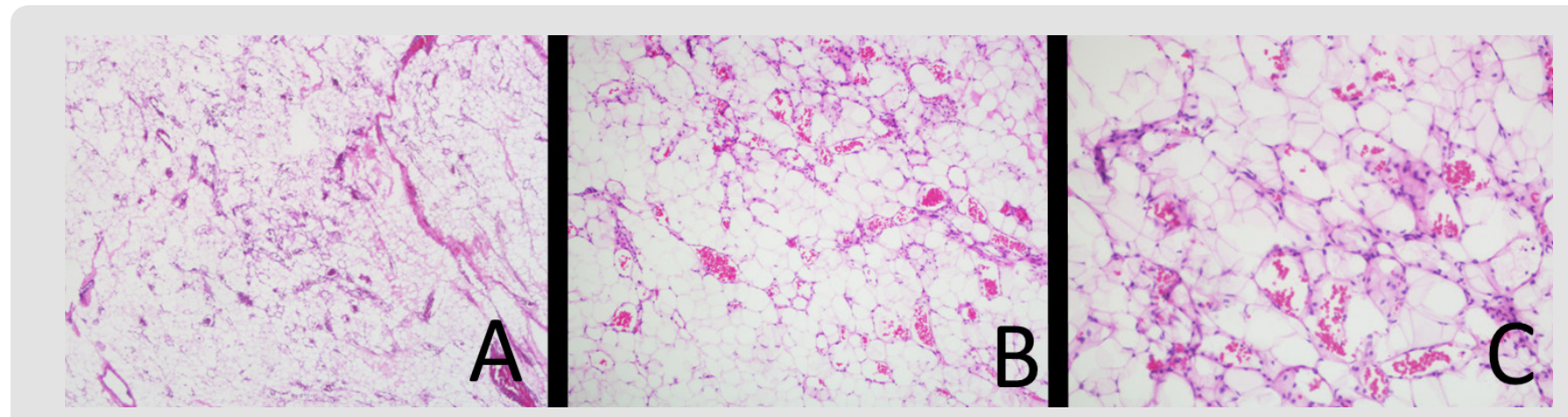

Figure 2:

Mature adipocytes and thin walled vessels, a number of which contain fibrin thrombi, x40, H\&E.

Mature adipocytes and thin walled vessels, x100, H\&E.

Mature adipocytes and branching capillary sized vessels, x200, H\&E.

\section{Discussion}

Angiolipomas are benign tumors which are usually locate subcutaneously at the extremity, trunk or neck [8]. SAL are uncommon lesions which are usually locate at the thoracic segment and posterior extradural region. SALs constitute $0.14-1.2 \%$ of spinal tumors, $2-3 \%$ of extradural tumors. Most common location of SAL is thoracic segment (78\%) [7]. In the literature there is debate about the pathophysiology of SAL. Histologically, SAL are 
considered as hamartoma 6, or duralmesenchymal benign tumor $[9,10]$. Mesenchymal stem cell may difference into lipoma or angioma. Mesenchymal cell differentiation may occur thought lipoma side or angioma side. The angiolipoma is an intermediate pathological entity of this differentiation [5]. Angiolipoma was first descripted by Howard and Helwig, and they classified this pathology into two sub-groups which are an infiltrative type and an encapsulated type [10]. Several risk factors have been descripted for growth of SAL.

Trauma, inflammatory stimuli and hormonal imbalance are descripted as etiological factor for acute tumor growth in the literature. Increased prevalence of peri-menopause patients is supporting that hormonal imbalance can be etiological risk factor for acute neurological deterioration of SAL as our case [7]. Other potential risk factors for acute neurological deterioration is pregnancy, weight gain and steroid treatment [11]. Hormone dependent and vascular characters of SAL are responsible for intermittent clinical course of remission and aggravation. Expansion of tumor may cause acute onset clinical symptoms due to thrombosis, intratumoralhemorrhage or steal phenomenon [12]. MRI is the most helpful diagnostic tool for SAL. But histopathological examination is essential for certain diagnosis. These tumors are slow growing benign lesions. Histologically, angiolipomas typically consist of two mesenchymal elements: mature adipocytes and thin walled-vessels, a number of which contain fibrin thrombi [13]. Kaposi's sarcoma and angiosarcoma should be considered when a cellular angiolipoma is seen microscopically [14]. Tumor recurrence after surgery reported as $1.1 \%$ by literature.

SAL is usually present by progressive neurological deficits $[3,7]$. Acute paraplegia due to SAL has been reported in only seven cases (Table 1) [9,10,12,15-17]. Pathogenesis of acute paraplegia was due to tumorhemorrhage in the five cases[12,15-18]. The underlying cause of tumorhemorrhage has hypothesized as increased blood flow due to exercise by some authors Tsutsumi, et al. [12,15]has been reported acute onset paraplegia of SAL case. The underlying cause of tumorhemorrhage has been reported as disruption of abnormal vessels by increased venous pressure due to pregnancy. Other hypotheses about acute onset symptoms are hemorrhage due to abnormal arterial vessel injury $[15,16]$ reported acute onset paraplegia caused by tumorhemorrhage due to antiplatelet therapy. In our case there was not tumorhemorrhage. But patient had weight gain due to immobilization because of lumbar stabilization operation and back pain. Spinal cord decompression is mandatory for acute onset neurological findings. When there is no neurological finding follow-up with radiological and clinical examination can be option. In previous cases complete neurological improvement after decompression within 48 hours achieved in four cases as our case $[10,12,15,16]$. In a previous cases, tumor was consist of adipose tissue and abnormal small vascular structures[12,15-19]. In our case, there is no active bleeding of tumor or abnormal vascular structures.

Table 1: Review of previously published cases on thoracic angiolipomas which are manifested with acute paraplegia.

\begin{tabular}{|c|c|c|c|c|c|c|c|c|c|}
\hline & \multirow{2}{*}{ Age } & \multirow{2}{*}{ Gender } & \multirow{2}{*}{ Duration } & \multicolumn{3}{|c|}{ Symptoms } & \multirow{2}{*}{ Location } & \multirow{2}{*}{$\mathrm{TH}$} & \multirow{2}{*}{ Recovery } \\
\hline & & & & BP & UD & SF & & & \\
\hline Anson, et al. [18] & 65 & M & $24 \mathrm{~h}$ & + & - & - & T1-T6 & - & Partial \\
\hline $\begin{array}{c}\text { Akhaddar, et al. } \\
\text { [19] }\end{array}$ & 47 & M & ND & + & + & + & $\mathrm{T} 2-\mathrm{T} 3$ & + & Complete \\
\hline $\begin{array}{c}\text { Sankaran, et al. } \\
{[17]}\end{array}$ & 77 & M & $48 \mathrm{~h}$ & + & + & + & T8-T11 & + & Complete \\
\hline $\begin{array}{c}\text { Tsutsumi, et al. } \\
{[12]}\end{array}$ & 26 & $\mathrm{~F}$ & $14 \mathrm{~h}$ & + & + & + & T3-T4 & + & Complete \\
\hline $\begin{array}{l}\text { Ramdasi, et al. } \\
{[16]}\end{array}$ & 58 & M & $48 \mathrm{~h}$ & + & + & + & C7-T1 & + & Complete \\
\hline $\begin{array}{l}\text { Mohammed, et } \\
\text { al. [10] }\end{array}$ & 35 & $\mathrm{~F}$ & ND & + & + & - & T5-T8 & + & Complete \\
\hline Lacour, et al. [9] & 17 & M & $36 \mathrm{~h}$ & + & + & + & T7-T12 & + & Partial \\
\hline Our case & 51 & $\mathrm{~F}$ & $24 \mathrm{~h}$ & + & - & - & T6-T9 & - & Complete \\
\hline
\end{tabular}

Note: BP:Back pain; UD: Urinary Dysfunction; SF: Sensorial Finding; TM:Tumor Haemorrhage; ND:NotDescriped

\section{Conclusion}

SAL is a rare entity which is composed of adipose tissue and vascular elements. Any factors that can creates alteration of hemodynamic status or adipose tissue may cause acute neurological finding. MRI is essential diagnostic tool for these lesions. Postoperative outcomes are excellent even at the complete paraplegia and subtotal resection.

\section{References}

1. Dogan S, Arslan E, Sahin S, Aksoy K, Aker S, et al. (2006) Lumbar spinal extradural angiolipomas. Two case reports. Neurologia medicochirurgica 46(3):157-160.

2. Gelabert Gonzalez M, Agulleiro Diaz J, Reyes Santias RM (2002) Spinal extradural angiolipoma, with a literature review. Child's nervous system : ChNS : official journal of the International Society for Pediatric Neurosurgery 18(12): 725-728. 
3. Sim K, Tsui A, Paldor I, Kaye AH, Gaillard F, et al. (2016) Four cases of spinal epidural angiolipoma. Journal of clinical neuroscience : official journal of the Neurosurgical Society of Australasia 25:134-139.

4. Samdani AF, Garonzik IM, Jallo G, Eberhart CG, Zahos P, et al. (2004) Spinal angiolipoma: case report and review of the literature. Actaneurochirurgica 146(3): 299-302.

5. Rkhami M, Kedous MA, Achoura S, Zehani A, Bahri K, et al. (2018) Epidural angiolipoma: A rare cause of spinal cord compression. International journal of surgery case reports 45: 72-76.

6. Yang X, Richard SA, Lei C, Liu J, Huang S, et al. (2018) Spinal extradura angiolipoma: A report of two cases and review of literature. Journal of spine surgery (Hong Kong) 4(2): 490-495.

7. Gelabert Gonzalez M, Garcia Allut A (2009) Spinal extradural angiolipoma: report of two cases and review of the literature. European spine journal : official publication of the European Spine Society, the European Spinal Deformity Society, and the European Section of the Cervical Spine Research Society 18(3): 324-335.

8. Benvenutti Regato M, De la Garza Ramos R, Caro Osorio E (2015) Thoracic epidural spinal angiolipoma with coexisting lumbar spinal stenosis: Case report and review of the literature. International journal of spine surgery 9: 67 .

9. Lacour M, Gilard V, Marguet F, Curey S, Perez A, et al. (2018) Sudden paraplegia due to spontaneous bleeding in a thoracic epidural angiolipoma and literature review. Neuro-Chirurgie 64(1): 73-75.

10. Mohammed ZI, Ahmed MM (2016) Spinal extradural angiolipoma manifested after normal vaginal delivery. BMC research notes 9: 132.

11. Guegan Y, Fardoun R, Launois B, Pecker J (1982) Spinal cord compression by extradural fat after prolonged corticosteroid therapy. Journal of neurosurgery 56(2): 267-269.

ISSN: 2574-1241

DOI: 10.26717/BJSTR.2020.27.004464

ÖcalÖzgür. Biomed J Sci \& Tech Res

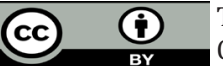

This work is licensed under Creative Commons Attribution 4.0 License

Submission Link: https://biomedres.us/submit-manuscript.php
12. Tsutsumi S, Nonaka Y, Abe Y, Yasumoto Y, Ito M, et al. (2011) Spinal angiolipoma in a pregnant woman presenting with acute epidural hemorrhage. Journal of clinical neuroscience : official journal of the Neurosurgical Society of Australasia 18(6): 849-851.

13. Dixon AY, McGregor DH, Lee SH (1981) Angiolipomas: an ultrastructural and clinicopathological study. Human pathology 12(8): 739-747.

14. Hunt SJ, Santa Cruz DJ, Barr RJ (1990) Cellular angiolipoma. The American journal of surgical pathology 14(1): 75-81.

15. Akhaddar A, Albouzidi A, Elmostarchid B, Gazzaz M, Boucetta M, et al. (2008) Sudden onset of paraplegia caused by hemorrhagic spinal epidural angiolipoma. A case report. European spine journal: official publication of the European Spine Society, the European Spinal Deformity Society, and the European Section of the Cervical Spine Research Society 17(Suppl 2): S296-298.

16. Ramdasi RV, Avinasha KM, Mahore A, Kawale J (2014) Spinal angiolipoma manifesting with apoplexy. BMJ case reports.

17. Sankaran V, Carey M, Shad A (2010) Traumatic bleeding of spinal angiolipoma presenting with subacuteparaparesis--A case report and histopathological aspects. British journal of neurosurgery 24(6): 714715 .

18. Anson JA, Cybulski GR, Reyes M (1990) Spinal extradural angiolipoma: a report of two cases and review of the literature. Surgical neurology 34(3): 173-178.

19. Akhaddar A, Gazzaz M, Derraz S (2000) [Spinal epidural angiolipomas: A rare cause of spinal cord compression. A report of 8 cases and review of the literature]. Neuro-Chirurgie 46(6): 523-533.

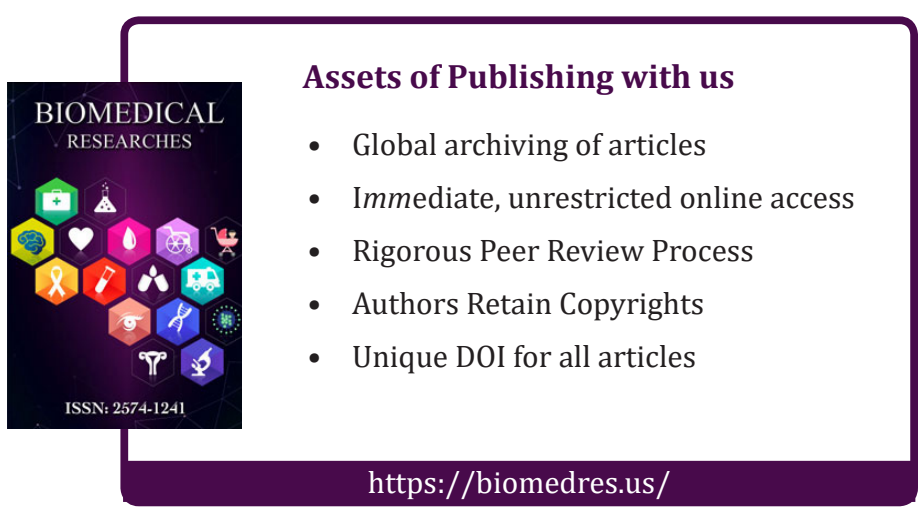

